Research Article

\title{
Supply Chain Contract Choice with Different Behavior Preferences of Retailer
}

\author{
Yonglong Wang (D, Xinyu Zheng, Jirong Cai, and Yuelong Zheng \\ School of Business Administration, Chongqing Technology and Business University, Chongqing 400067, China \\ Correspondence should be addressed to Yonglong Wang; wyl@ctbu.edu.cn
}

Received 23 September 2021; Accepted 9 October 2021; Published 30 October 2021

Academic Editor: Daqing Gong

Copyright (c) 2021 Yonglong Wang et al. This is an open access article distributed under the Creative Commons Attribution License, which permits unrestricted use, distribution, and reproduction in any medium, provided the original work is properly cited.

\begin{abstract}
Retailer may exhibit irrationality when facing the risk of demand uncertainty; therefore, we consider four retailer behavioral preferences: risk neutral (RN), waste aversion (WA), stockout aversion (SA), and stockout-waste aversion (SW). The decisionmaking and contract choice of upstream and downstream enterprises in cases where demand depends on supplier's effort are studied. The results show that if the retailer has only SA or RN preferences, then the supplier prefers to choose a wholesale price contract, while the retailer does the opposite, if the retailer has only WA, then the supplier prefers to choose a revenue sharing contract, but the retailer's contract choice depends on the degree of waste aversion, and if the retailer has SW, then the contract choice of upstream and downstream enterprises is related to the degree of waste aversion and stockout aversion.
\end{abstract}

\section{Introduction}

Because different contracts may bring different benefits to supply chain participants, different participants choose different contracts. The concept of supply chain contract choice comes from the term "prefer" proposed by Cachon and Lariviere [1], who noted that the supplier prefers contracts that is more profitable to him based on different circumstances. However, the research on contract choice is still very limited, and most of the existing literature focuses on the choice between wholesale price contract and revenue-sharing contract, which is also the content of this paper. The reason for choosing the two contracts in this paper is that the two contracts are simple and the two contracts are widely used in real life.

To weigh the advantages and disadvantages of the above two contracts, Cachon and Lariviere [1] analyze the contract selection of upstream enterprises when product quantity and retailer effort influence product price. In addition, Pan et al. [2] study the contract choice problem under different dominant agents using a system constructed by two upstream enterprises and a single downstream enterprise or a single upstream enterprise and two downstream enterprises. $\mathrm{Xu}$ [3] discusses the contract choice under a three-level tourism supply chain dominated by a travel agency. Jin et al. [4] study the contract choice under different agents who make decisions about effort when demand is affected by retail price and effort and the retailer has financial constraints. Chakraborty et al. [5] consider the situation in which the retailer sells two alternative products at the same time and where the market demand depends on the retail price of the two products, and they study the contract choice problem under different power structures. Lu et al. [6] analyze the influence of advertising effort efficiency and channel member patience on contract choice in the context of downstream enterprises leading and advertising having a dynamic influence. Meng and Huang [7] discuss the contract choice of upstream and downstream enterprises in the case of two upstream logistics service providers.

However, the above studies take the participants' perfect rationality as the premise of their research and do not consider the possibility that the participants may have limited rationality [8]. In fact, there is risk in demand [9], and the behavior of decision makers may be affected by demand [10]. In particular, Schweitzer and Cachon [11] point out that retailers may have a waste aversion preference because they do not like carrying excess inventory, or they may have a stockout aversion preference because they dislike shortages. 
Therefore, the two behavior preferences are introduced into the supply chain, especially considering that random demand is affected by the supplier's effort (e.g., advertising, quality, services to enhance the physical store, and after-sales service [12-15]). This paper studies the decision-making and contract choice of upstream and downstream enterprises in the supply chain under different behavior preferences of the retailer.

\section{Model Assumptions}

The model is based on the following assumptions:

(1) The risk-neutral supplier is the leader.

(2) Four retailer behavioral preferences are considered: risk neutral (RN), waste aversion (WA), stockout aversion (SA), and stockout-waste aversion (SW).

(3) Market demand is $D=e \xi[12]$, where $e$ is the effort input level of the supplier and $\xi$ is the random disturbance factor. Because of the complexity of the model structure, the model cannot be solved; to simplify the model and obtain more valuable conclusions, the methods of Taylor [12] and Yu and Wan [16] are used, and $\xi$ is assumed to follow the distribution of $U(0, B)$.

(4) $p>w>c>v$.

The symbols of this article are summarized in Table 1.

\section{Model Construction}

3.1. RS Model. Under the RS model, it is assumed that the retailer gives $(1-\phi)$ times its own sales revenue to the supplier in exchange for a lower wholesale price $w=\phi c$ [1], where $0<\phi \leq 1$ and $\phi p>v$. When the random demand depends on the effort of the supplier, the retailer's expected sales volume $S(q, e)$, inventory volume $L(q, e)$, and shortage volume $N(q, e)$ are

$$
\begin{aligned}
S(q, e) & =E[\min (q, e \xi)], \\
L(q, e) & =E(q-e \xi)^{+}=q-S(q, e), \\
N(q, e) & =E(e \xi-q)^{+}=E(e \xi)-S(q, e) .
\end{aligned}
$$

The expected profits of upstream and downstream enterprises are

$$
\begin{aligned}
\pi_{S-j}^{R S}(\phi, e) & =(1-\phi) p S(q, e)-(1-\phi) c q-k e^{2}, \\
\pi_{R-j}^{R S}(q) & =\phi p S(q, e)+v L(q, e)-\phi c q,
\end{aligned}
$$

where $j \in\{\mathrm{RN}, \mathrm{WA}, \mathrm{SA}, \mathrm{SW}\}$.

3.1.1. SW Model. If the retailer has an SW preference, then the expected utility of the retailer is as calculated below:

$$
U_{R-S W}^{\mathrm{RS}}(q)=\phi p S(q, e)+v L(q, e)-\lambda N(q, e)-\beta L(q, e)-\phi c q .
$$

From equation (3), we obtain

$$
\begin{aligned}
\frac{\partial U_{R-S W}^{\mathrm{RS}}}{\partial q} & =\frac{q(v-\beta-\lambda-p \phi)+B e[\lambda+\phi(p-c)]}{B e}, \\
\frac{\partial^{2} U_{R-S W}^{\mathrm{RS}}}{\partial q^{2}} & =\frac{p \phi-v+\lambda+\beta}{-B e}<0 .
\end{aligned}
$$

From equation (3), we can see that $U_{R-S W}^{\mathrm{RS}}$ is a concave function of $q$. Therefore, if $\partial U_{R-S W}^{\mathrm{RS}} / \partial q=0$, the unique optimal $q_{\mathrm{SW}}^{\mathrm{RS}}$ can be obtained:

$$
q_{s W}^{R S^{*}}=\frac{B e[\lambda+\phi(p-c)]}{\phi p+\lambda+\beta-v} .
$$

By substituting $q_{\mathrm{SW}}^{\mathrm{RS}}$ into equation (2), then

$$
\max _{\phi, e} \pi_{S-S W}^{\mathrm{RS}}=\frac{\operatorname{Bep}(1-\phi)(2 \beta+\lambda-2 v+c \phi+p \phi)[\lambda+\phi(p-c)]}{2(\phi p+\lambda+\beta-v)^{2}}-\frac{\operatorname{Bec}(1-\phi)[\lambda+\phi(p-c)]}{\phi p+\lambda+\beta-v}-k e^{2} .
$$

From equation (6), we obtain

$$
\begin{aligned}
\frac{\partial \pi_{S-S W}^{\mathrm{RS}}}{\partial e}= & \frac{B p(1-\phi)(2 \beta+\lambda-2 v+c \phi+p \phi)[\lambda+\phi(p-c)]}{2(\phi p+\lambda+\beta-v)^{2}}-\frac{B c(1-\phi)[\lambda+\phi(p-c)]}{\phi p+\lambda+\beta-v}-2 k e, \\
\frac{\partial \pi_{S-S W}^{\mathrm{RS}}}{\partial \phi}= & B e\left\{2 c(p-c)(\phi-1)(\phi p+\lambda+\beta-v)^{2}+p(p-c)(1-\phi)(\phi p+\lambda+\beta-v)\right\} \\
& \times(2 \beta+\lambda-2 v+c \phi+p \phi)+2 c p(1-\phi)(\phi p+\lambda+\beta-v)[\lambda+\phi(p-c)] \\
& +p(p+c)(1-\phi)(\phi p+\lambda+\beta-v)[\lambda+\phi(p-c)]+2 c(\phi p+\lambda+\beta-v)^{2} \\
& \times[\lambda+\phi(p-c)]-2 p^{2}(1-\phi)(\phi p+\phi c+\lambda+2 \beta-2 v)[\lambda+\phi(p-c)] \\
& -p(\phi p+\lambda+\beta-v)(\phi p+\phi c+\lambda+2 \beta-2 v)[\lambda+\phi(p-c)] .
\end{aligned}
$$


TABLE 1: Symbols and meanings.

\begin{tabular}{lc}
\hline$w$ & Wholesale price \\
$p$ & Retail price \\
$e$ & Effort \\
$\beta$ & Waste aversion coefficient \\
$\mathrm{RN}$ & Risk neutral \\
$\mathrm{SA}$ & Stockout averse preference \\
$\mathrm{WP}$ & Wholesale price contract \\
$U_{R-i}^{j}$ & Under $j$ contract, the expected utility obtained by the retailer him or herself when he or she has $i$ preference \\
$\pi_{R-i}^{j}$ & Under $j$ contract, the expected profit obtained by the retailer him or herself when he or she has $i$ preference \\
$c$ & Production costs \\
$q$ & Order quantity \\
$v$ & Salvage value \\
$\lambda$ & Stockout aversion coefficient \\
$\mathrm{WA}$ & Waste averse preference \\
SW & Stockout-waste averse preference \\
$\mathrm{RS}$ & Revenue-sharing contract \\
$\pi_{S-i}^{j}$ & Under $j$ contract, the expected profit of the supplier when the retailer has $i$ preference $j \in\{\mathrm{WP}, \mathrm{RS}\}$ and $i \in\{\mathrm{RN}, \mathrm{WA}, \mathrm{SA}, \mathrm{SW}\}$ \\
\hline
\end{tabular}

The optimal $e_{\mathrm{SW}}^{\mathrm{RS}}$ and $\phi_{\mathrm{SW}}^{\mathrm{RS}}$ can be obtained by making $\partial \pi_{S-S W}^{\mathrm{RS}} / \partial e=0$ and $\partial \pi_{S-S W}^{\mathrm{RS}} / \partial \phi=0$, and the optimal expected profits of the upstream and downstream enterprises are

$$
\begin{aligned}
\pi_{S-S W}^{R S^{*}} & =\frac{B e_{S W}^{\mathrm{RS}} p\left(1-\phi_{\mathrm{SW}}^{\mathrm{RS}}\right)\left(p \phi_{\mathrm{SW}}^{\mathrm{RS}}+c \phi_{\mathrm{SW}}^{\mathrm{RS}}+\lambda+2 \beta-2 v\right)\left[\lambda+\phi_{\mathrm{SW}}^{\mathrm{RS}}(p-c)\right]}{2\left(\phi_{\mathrm{SW}}^{\mathrm{RS}} p-v+\lambda+\beta\right)^{2}}-\frac{B e c\left(1-\phi_{\mathrm{SW}}^{\mathrm{RS}}\right)\left[\lambda+\phi_{\mathrm{SW}}^{\mathrm{RS}^{*}}(p-c)\right]}{\phi_{S W}^{\mathrm{RS}} p-v+\lambda+\beta}-k\left(e_{\mathrm{SW}}^{\mathrm{RS}}\right)^{2}, \\
\pi_{R-S W}^{R S^{*}} & =\frac{\left[B e_{\mathrm{SW}}^{\mathrm{RS}}\left[\lambda+\phi_{\mathrm{SW}}^{\mathrm{RS}}(p-c)\right]\left\{v\left[\lambda-\phi_{\mathrm{SW}}^{\mathrm{RS}}(p-c)\right]+\phi_{\mathrm{SW}}^{\mathrm{RS}}\left[p\left(2 \beta+\lambda+\phi_{\mathrm{SW}}^{\mathrm{RS}} p\right)-c\left(2 \beta+2 \lambda+\phi_{\mathrm{SW}}^{\mathrm{RS}^{*}} p\right)\right]\right\}\right]}{2\left(\phi_{\mathrm{SW}}^{\mathrm{RS}} p-v+\lambda+\beta\right)^{2}} .
\end{aligned}
$$

3.1.2. WA Model. If the retailer is WA, that is, $\lambda=0$ and $\beta>0$, then (7) can be used to obtain the optimal $e_{\mathrm{WA}}^{\mathrm{RS}}$ and $\phi_{\mathrm{WA}}^{\mathrm{RS}}$ which are given as

$$
\begin{array}{r}
\frac{4 k e(\phi p+\beta-v)^{2}-B \phi(1-\phi)(p-c)^{2}(p \phi+2 \beta-2 v)}{\phi p+\beta-v}=0, \\
\frac{B e(p-c)\left\{3 p \beta \phi^{2}+p^{2} \phi^{3}+\left(v^{2}+\beta^{2}\right)(4 \phi-2)+v\left[\beta(4-8 \phi)-3 p \phi^{2}\right]\right\}}{\phi p+\beta-v}=0 .
\end{array}
$$

At this point, $q_{\mathrm{WA}}^{\mathrm{RS}}, \pi_{S-\mathrm{WA}}^{\mathrm{RS}}$, and $\pi_{R-\mathrm{WA}}^{\mathrm{RS}}$ are

$$
\begin{aligned}
q_{\mathrm{WA}}^{\mathrm{RS}} & =\frac{B e_{\mathrm{WA}}^{\mathrm{RS}} \phi_{\mathrm{WA}}^{\mathrm{RS}}(p-c)}{p \phi_{\mathrm{WA}}^{\mathrm{RS}}+\beta-v}, \\
\pi_{S-\mathrm{WA}}^{\mathrm{RS}} & =\frac{B e p \phi_{\mathrm{WA}}^{\mathrm{RS}}(p-c)\left(1-\phi_{\mathrm{WA}}^{\mathrm{RS}}\right)\left(p \phi_{\mathrm{WA}}^{\mathrm{RS}^{*}}+c \phi_{\mathrm{WA}}^{\mathrm{RS}^{*}}+2 \beta-2 v\right)}{2\left(\phi_{\mathrm{WA}}^{\mathrm{RS}} p-v+\beta\right)^{2}}-\frac{B e c \phi_{\mathrm{WA}}^{\mathrm{RS}^{*}}(p-c)\left(1-\phi_{\mathrm{WA}}^{\mathrm{RS}^{*}}\right)}{\phi_{\mathrm{WA}}^{\mathrm{RS}} p-v+\beta}-k\left(e_{\mathrm{WA}}^{\mathrm{RS}^{*}}\right)^{2}, \\
\pi_{R-\mathrm{WA}}^{\mathrm{RS} *} & =\frac{B e \phi_{\mathrm{WA}}^{\mathrm{RS}}(p-c)\left\{v \phi_{\mathrm{WA}}^{\mathrm{RS}}(c-p)+\phi_{\mathrm{WA}}^{\mathrm{RS}}\left[p\left(2 \beta+\phi_{\mathrm{WA}}^{\mathrm{RS}} p\right)-c\left(2 \beta+p \phi_{\mathrm{WA}}^{\mathrm{RS}^{*}}\right)\right]\right\}}{2\left(\phi_{\mathrm{WA}}^{\mathrm{RS}} p-v+\beta\right)^{2}} .
\end{aligned}
$$


3.1.3. SA Model. If the retailer is SA, that is, $\lambda>0$ and $\beta=0$, then (7) can be used to obtain the optimal $e_{\mathrm{SA}}^{\mathrm{RS}^{*}}$ and $\phi_{\mathrm{SA}}^{\mathrm{RS}^{*}}$ which are given as

$$
\begin{aligned}
& \frac{B p(1-\phi)(\lambda-2 v+c \phi+p \phi)[\lambda+\phi(p-c)]}{2(\phi p+\lambda-v)^{2}}-\frac{B c(1-\phi)[\lambda+\phi(p-c)]}{\phi p+\lambda-v}-2 k e=0 \\
& B e\left\{2 c(p-c)(\phi-1)(\phi p+\lambda-v)^{2}+p(p-c)(1-\phi)(\phi p+\lambda-v) \times(\lambda-2 v+c \phi+p \phi)+2 c p(1-\phi)(\phi p+\lambda-v)\right. \\
& \quad[\lambda+\phi(p-c)]+p(p+c)(1-\phi)(\phi p+\lambda-v)[\lambda+\phi(p-c)]+2 c(\phi p+\lambda-v)^{2} \times[\lambda+\phi(p-c)] \\
& -2 p^{2}(1-\phi)(\phi p+\phi c+\lambda-2 v)[\lambda+\phi(p-c)]-p(\phi p+\lambda-v)(\phi p+\phi c+\lambda-2 v)[\lambda+\phi(p-c)]=0 .
\end{aligned}
$$

In the same way as above, the optimal $q_{\mathrm{SA}}^{\mathrm{RS}^{*}}, \pi_{S-S A}^{\mathrm{RS}}$, and $\pi_{R-\mathrm{SA}}^{\mathrm{RS}}$ can be obtained.

3.1.4. $R N$ Model. If the retailer is $\mathrm{RN}$, that is, $\lambda>0$ and $\beta=0$, then (7) can be used to obtain the optimal $e_{\mathrm{RN}}^{\mathrm{RS}}$ and $\phi_{\mathrm{RN}}^{\mathrm{RS}}$ which is given as

$$
\begin{array}{r}
\frac{B e(p-c)^{2}\left[\phi^{3} p^{2}+v^{2}(4 \phi-2)-3 p v \phi^{2}\right]}{2(v-\phi p)^{3}}=0, \\
\frac{B \phi(1-\phi)(p-c)^{2}(\phi p-2 v)-2 k e(\phi p-v)^{2}}{2(v-\phi p)^{2}}-k e=0 .
\end{array}
$$

In the same way as above, the optimal $q_{\mathrm{RN}}^{\mathrm{RS}}, \pi_{S-\mathrm{RN}}^{\mathrm{RS}}$, and $\pi_{R-\mathrm{RN}}^{\mathrm{RS}}$ can be obtained.

3.2. WP Model. If WP is adopted between upstream and downstream enterprises, then the decision models under the four different behavior preferences are as follows.

\subsubsection{RN Model}

Step 1: $\max _{w-\mathrm{xN}}^{\mathrm{WP}}(w, e)=(w-c) q-k e^{2}$

Step 2: $\max _{q} \pi_{R-\mathrm{RN}}^{\mathrm{WP}}(q \mid w, e)=p S(q, e)+v L(q, e)-w q$

\subsubsection{WA Model}

Step 1: $\max _{w, e} \pi_{S-\mathrm{WA}}^{\mathrm{WP}}(w, e)=(w-c) q-k e^{2}$

Step 2: ${ }^{w, e} \max U_{R-\mathrm{WA}}^{\mathrm{WP}}(q \mid w, e)=p S(q, e)+v L(q, e)-$ $\beta L(q, e)-w q^{q}$

\subsubsection{SA Model}

Step 1: $\max \pi_{S-S A}^{\mathrm{WP}}(w, e)=(w-c) q-k e^{2}$

Step $2: \quad \max _{R-\mathrm{SA}}^{\mathrm{WP}}(q \mid w, e)=p S(q, e)+v L(q, e)-$ $\lambda N(q, e)-w q^{q}$

\subsubsection{SW Model}

Step 1: $\max _{w, e} \pi_{S-S W}^{\mathrm{WP}}(w, e)=(w-c) q-k e^{2}$
Step 2: $\max U_{R-S \mathrm{WP}}^{\mathrm{WP}}(q \mid w, e)=p S(q, e)+v L(q, e)-\lambda N$ $(q, e)-\beta L^{q}(q, e)-w q$

If the retailer is SW, let $\partial U_{R-S W}^{\mathrm{WP}} / \partial q=0$; we can obtain

$$
q_{\mathrm{SW}}^{\mathrm{WP}}=\frac{B e(p-w+\lambda)}{p-v+\lambda+\beta} .
$$

By substituting $q_{\mathrm{SW}}^{\mathrm{WP}^{*}}$ into $\pi_{S-\mathrm{SW}}^{\mathrm{WP}}(w, e)$, then

$$
\max _{w, e} \pi_{2 S}^{\mathrm{SW}}(w, e)=\frac{B e(w-c)(p-w+\lambda)}{p-v+\beta+\lambda}-k e^{2} .
$$
obtain

Let $\partial \pi_{S-S W}^{\mathrm{WP}} / \partial w=0$ and $\partial \pi_{S-S W}^{\mathrm{WP}} / \partial e=0$, and we can

$$
\begin{aligned}
w^{\mathrm{SW}^{*}} & =\frac{p+c+\lambda}{2}, \\
e_{\mathrm{SW}}^{\mathrm{WP}^{*}} & =\frac{B(p-c+\lambda)^{2}}{8 k(p-v+\beta+\lambda)} .
\end{aligned}
$$

By substituting $w^{\mathrm{SW}^{*}}$ and $e_{\mathrm{SW}}^{\mathrm{WP}}$ into $q_{\mathrm{SW}}^{\mathrm{WP}^{*}}, \pi_{S-\mathrm{SW}}^{\mathrm{WP}}$, and $\pi_{R-S W}^{\mathrm{WP}}$, so you can get the result of the fourth row in Table 2 . In the same way as above, the Nash equilibrium for each of the other three behavioral preference models under WP can be obtained by using the reverse induction method; therefore, it is omitted. The results are shown in Table 2 .

\section{Numerical Simulation Analysis}

Due to the complexity of the results obtained under the RS model, we cannot analyze them through theoretical derivation. Therefore, in this section, we use the method of numerical simulation to obtain more valuable conclusions. Without loss of generality, we take $c=1, v=0.5, k=2$, $B=50$, and $p=5$.

From Figures 1-4, we can obtain Lemma 1 and Proposition 1.

Lemma 1. If the retailer has $S A$, (1) under the WP model, $q_{S A}^{W P^{*}}$ increases with respect to $\lambda$, but $q_{S A}^{R S^{*}}$ decreases with respect to $\lambda$ under the RS, (2) under both the WP and RS models, $e_{S A}^{W P^{*}}$ and $e_{S A}^{R S^{*}}$ are increasing with respect to $\lambda$, and (3) 


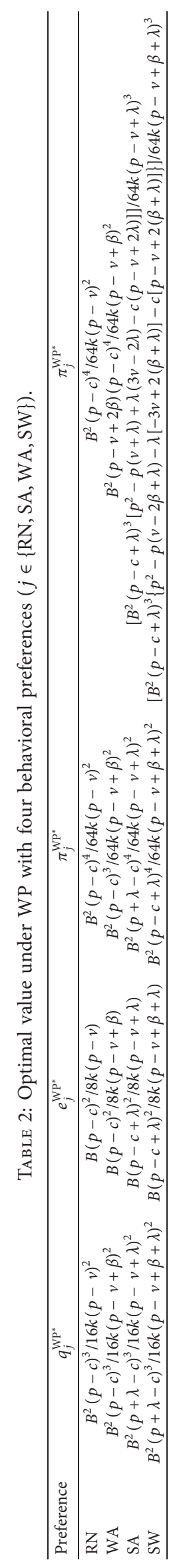




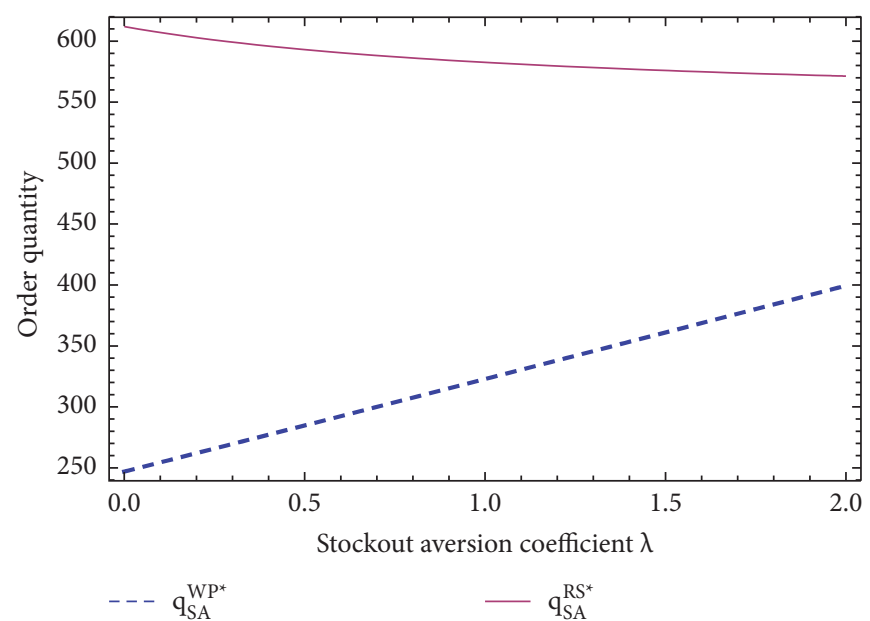

Figure 1: Effect of $\lambda$ on order quantity.

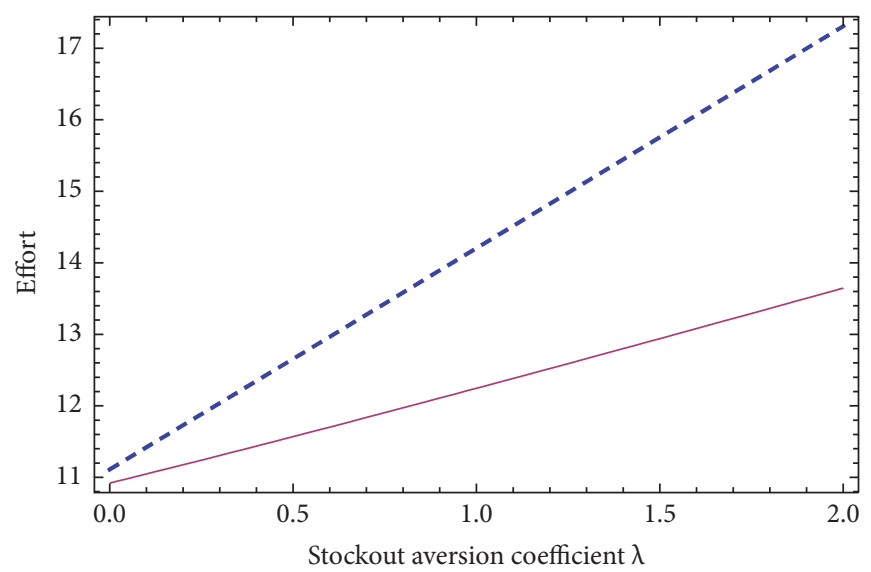

$$
---e_{S A}^{W P^{*}} \quad-e_{S A}^{R S^{*}}
$$

Figure 2: Effect of $\lambda$ on effort.

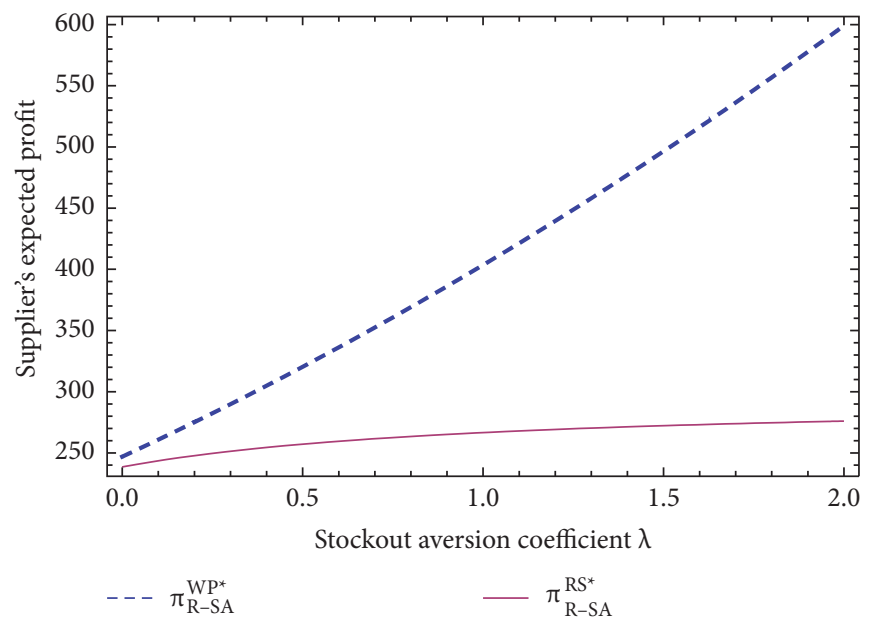

Figure 3: Effect of $\lambda$ on supplier's expected profit.

under both the WP and RS models, $\pi_{S-S A}^{W P^{*}}$ and $\pi_{S-S A}^{R S^{*}}$ are increasing with respect to $\lambda$, while $\pi_{R-S A}^{W P^{*}}$ and $\pi_{R-S A}^{R S^{*}}$ are decreasing with respect to $\lambda$.
Proposition 1. If the retailer is $S A(R N)$, then compared with the WP model, (1) the retailer orders more under the RS model, (2) less effort (expected profit) is made by the supplier 


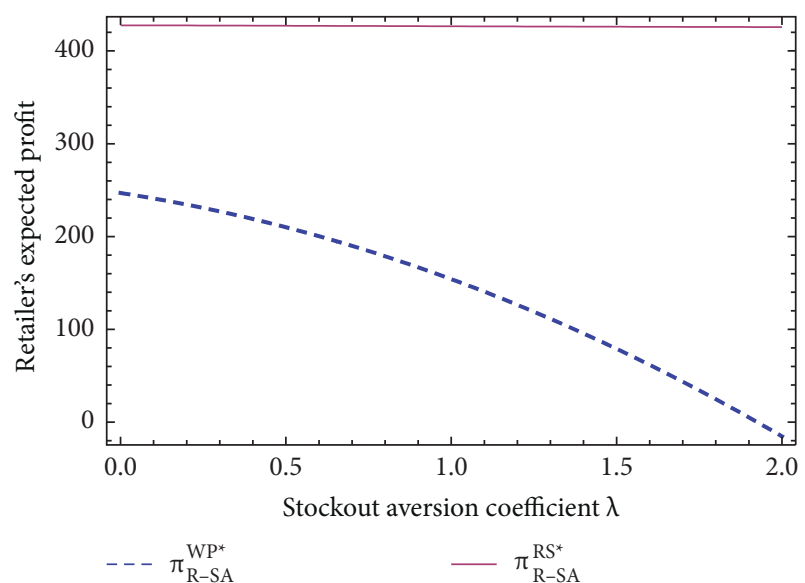

Figure 4: Effect of $\lambda$ on retailer's expected profit.

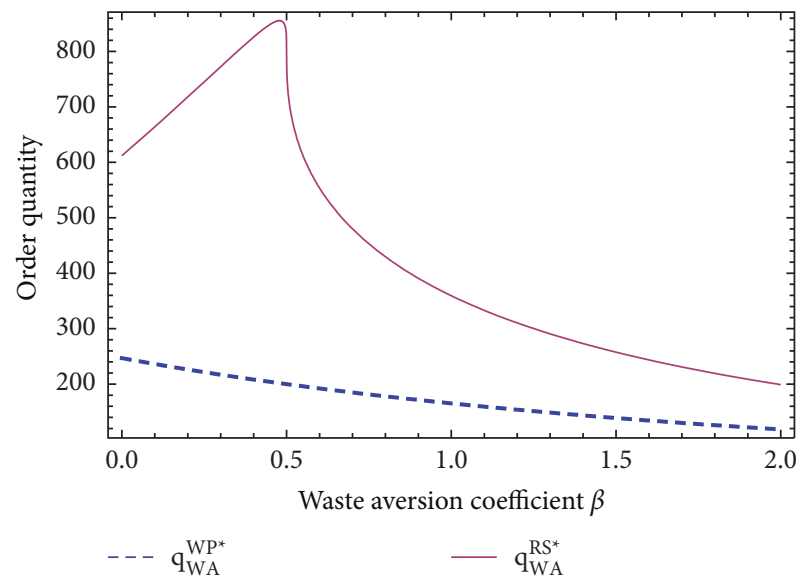

FIGURE 5: Effect of $\beta$ on order quantity.

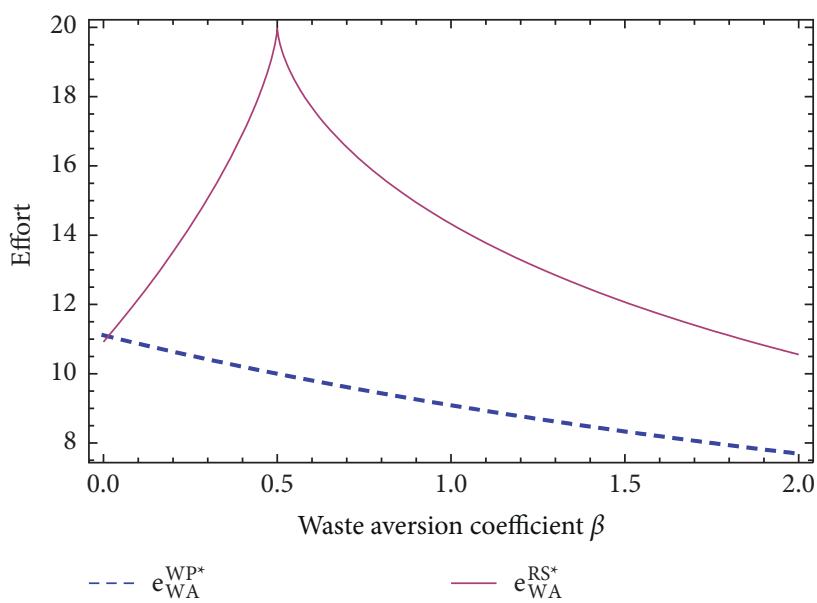

Figure 6: Effect of $\beta$ on effort.

under the RS model, and (3) the retailer has higher expected profit under the RS model.

From Figures 5-8, we can obtain Lemma 2 and Proposition 2

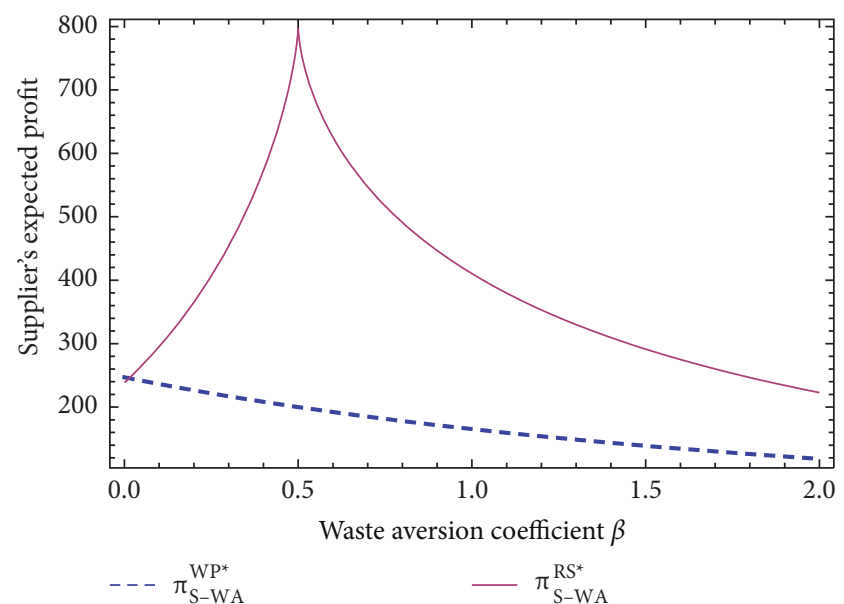

Figure 7: Effect of $\beta$ on supplier's expected profit.

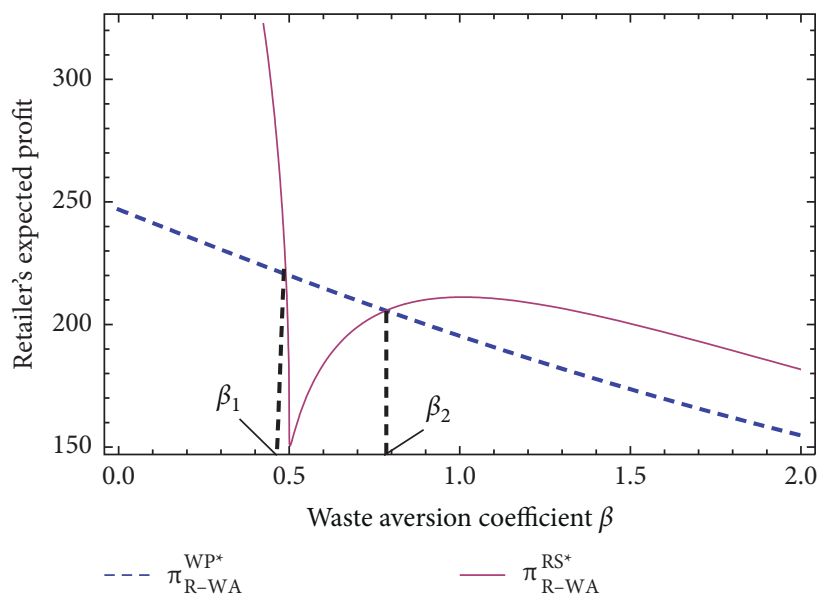

Figure 8: Effect of $\beta$ on retailer's expected profit.

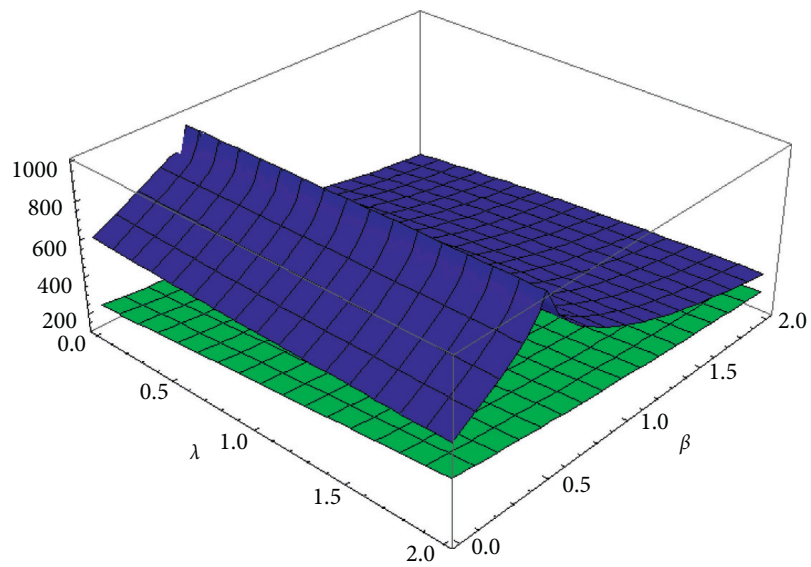

$\mathrm{qSW}_{\mathrm{SW}}^{\mathrm{WP}}$

$\mathrm{q}_{\mathrm{SW}}^{\mathrm{RS}}$

Figure 9: Effect of $\lambda$ and $\beta$ on order quantity.

Lemma 2. If the retailer has WA, the following is obtained. (1) Under the WP model, both $q_{W A}^{W P^{*}}$ and $e_{W A}^{W P^{*}}$ are decreasing functions of $\beta$. However, under the RS model, both $q_{W A}^{R S^{*}}$ and 


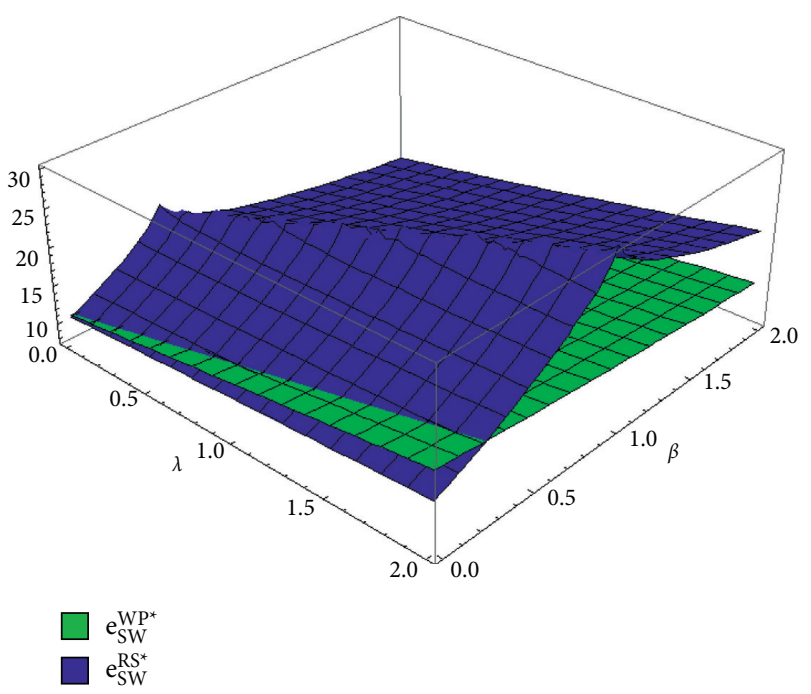

Figure 10: Effect of $\lambda$ and $\beta$ on effort.

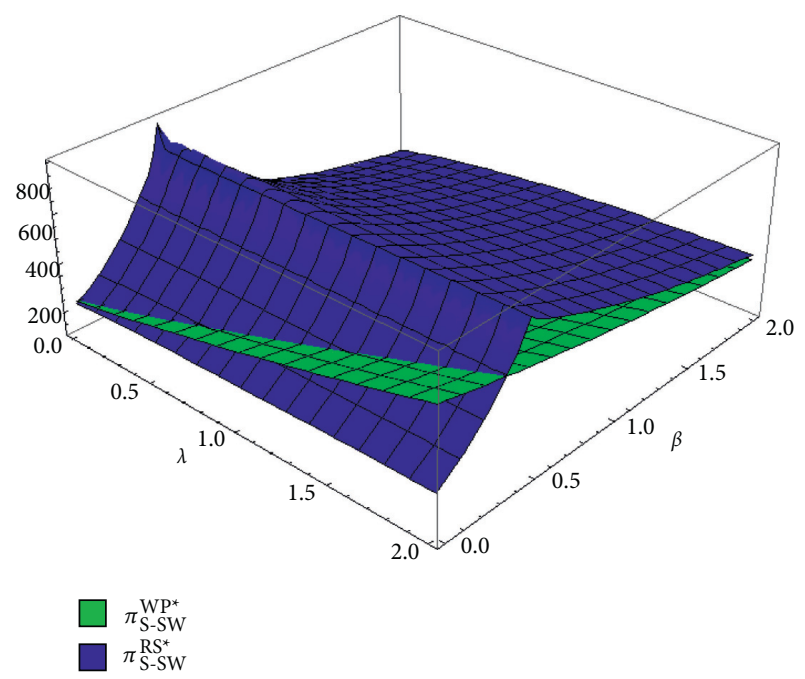

Figure 11: Effect of $\lambda$ and $\beta$ on the supplier's expected profit.

$e_{W A}^{R S^{*}}$ are first increasing and then decreasing with an increase in $\beta$. (2) Under the WP model, $\pi_{S-W A}^{W P^{*}}$ is a decreasing function of $\beta$. However, under the RS model, $\pi_{S-W A}^{R S^{*}}$ is first increasing and then decreasing with an increase in $\beta$. (3) Under the WP model, $\pi_{R-W A}^{W P^{*}}$ is a decreasing function of $\beta$, while under the $R S$ model, with the increase in $\beta$, there is a tendency for expected profit to decrease first, then increase, and then decrease.

Proposition 2. If the retailer has WA, then compared with the WP model, (1) the retailer orders more under the RS model, (2) supplier invests more effort under the RS model, (3) the expected profit of the supplier under the RS model is greater, and (4) the size of the retailer's expected profit between the above two contracts is related to $\beta$; there are thresholds $\beta_{1}$ and $\beta_{2}$ such that $\beta_{1}<\beta_{2}$, and if $\beta<\beta_{1}$ or $\beta>\beta_{2}$, its expected profit under the RS is greater, whereas when $\beta_{1}<\beta<\beta_{2}$, the expected profit under the WP model is greater.

From Figures 9-12, we can obtain Proposition 3.

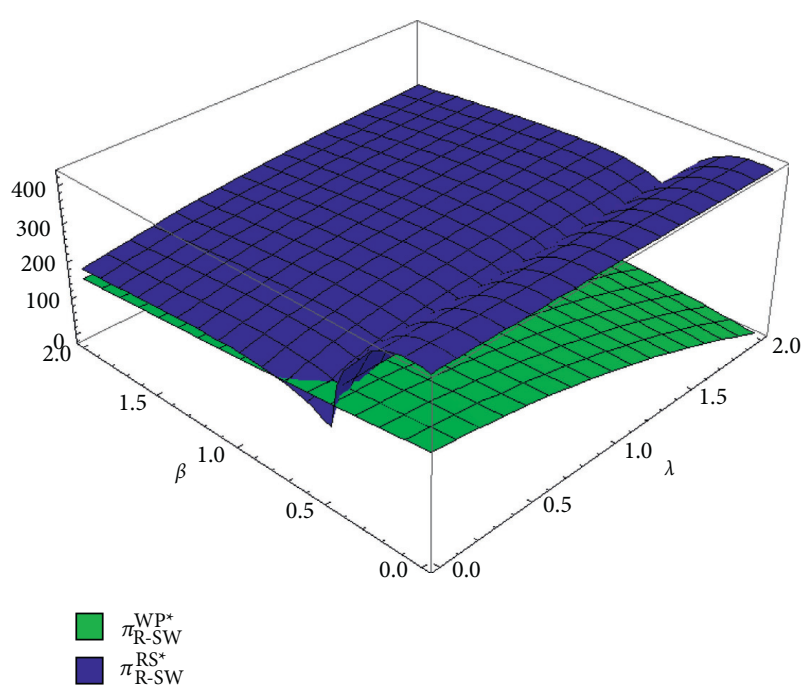

FIgURE 12: Effect of $\lambda$ and $\beta$ on the retailer's expected profit.

Proposition 3. If the retailer has $S W$, (1) the retailer orders more under the RS model, (2) when $\beta$ is small, then the supplier's effort (expected profit) under the WP model may be greater than under the RS model, and most of the time it is greater in the RS model, and (3) when $\beta$ is medium and $\lambda$ is small, then the retailer's expected profit under the WP model may be greater, and most of the time it is greater in the RS model.

\section{Conclusion}

In this paper, four situations in which the retailer has behavioral preferences are considered in the case of random demand affected by supplier's effort. Based on the WP and RS models, the influence of the retailer's different behavior preferences on the decision-making and contract choice of upstream and downstream enterprises is discussed.

The results show the following. (1) When the retailer only has SA (RN), the supplier's effort investment level under the WP model is higher, and the retailer's order quantity under the RS model is larger. (2) When the retailer only has WA, the supplier's effort input level and the retailer's order quantity under the RS model will be larger. (3) When the retailer has SW, the retailer will order more under the RS model, and the supplier's effort input level between the two contracts depends on the degree of waste aversion and stockout aversion. (4) When the retailer has only SA (RN), the supplier's expected profit under the WP model is greater, while the retailer's expected profit is lower. (5) When the retailer has only WA, the supplier's expected profit under the RS model is greater, but the expected profit of the retailer between the two contracts depends on the degree of waste aversion. (6) When the retailer has SW, the expected profit of both the retailer and supplier between the two contracts is related to the degree of waste aversion and stockout aversion.

Demand is often the private information for retailers $[17,18]$, so the impact of demand information sharing on 
supply chain contract choice can be considered in future studies.

\section{Data Availability}

The data used to support the findings of this study are included within the article.

\section{Conflicts of Interest}

The authors declare that they have no conflicts of interest.

\section{Acknowledgments}

This work was supported by the Humanities and Social Science Research Project of Ministry of Education of China (20XJC630007), Chongqing Natural Science Foundation (Basic Research and Frontier Exploration Special Project) Surface Project (cstc2019jcyj-msxmX0112), China Postdoctoral Science Foundation Funded Project (2020M673154), and Project of Science and Technology Research Program of Chongqing Education Commission of China (KJQN202000809).

\section{References}

[1] G. P. Cachon and M. A. Lariviere, "Supply chain coordination with revenue-sharing contracts: strengths and limitations," Management Science, vol. 51, no. 1, pp. 30-44, 2005.

[2] K. Pan, K. K. Lai, S. C. H. Leung, and D. Xiao, "Revenuesharing versus wholesale price mechanisms under different channel power structures," European Journal of Operational Research, vol. 203, no. 2, pp. 532-538, 2010.

[3] N. Xu, "Revenue sharing contract versus wholesale price contract in a tourism supply chain," International Journal of Supply Chain and Operations Resilience, vol. 2, no. 2, pp. 144-165, 2016.

[4] Y. Jin, S. Wang, and Q. Hu, "Contract type and decision right of sales promotion in supply chain management with a capital constrained retailer," European Journal of Operational Research, vol. 240, no. 2, pp. 415-424, 2015.

[5] T. Chakraborty, S. S. Chauhan, and N. Vidyarthi, "Coordination and competition in a common retailer channel: wholesale price versus revenue-sharing mechanisms," International Journal of Production Economics, vol. 166, pp. 103-118, 2015.

[6] F. Lu, J. Zhang, and W. Tang, "Wholesale price contract versus consignment contract in a supply chain considering dynamic advertising," International Transactions in Operational Research, vol. 26, no. 5, pp. 1977-2003, 2019.

[7] L. Meng and Z. Huang, "Research on the supply chain contract choice strategy of two-stage logistics service supply chain," Journal of Chongqing University (Social Science Edition), vol. 18, no. 3, pp. 64-72, 2012.

[8] A. L. Awaga, W. Xu, L. Liu, and Y. Zhang, "Evolutionary game of green manufacturing mode of enterprises under the influence of government reward and punishment," Advances in Production Engineering \& Management, vol. 15, no. 4, pp. 416-430, 2020.

[9] X. Fang, R. Wang, F. J. Yuan, Y. Gong, J. R. Cai, and Y. L. Wang, "Modelling and simulation of fresh-product supply chain considering random circulation losses," International Journal of Simulation Modelling, vol. 19, no. 1, pp. 169-177, 2020.
[10] A. Burinskiene, "New challenges for supply chain: electronic invoicing and its use perspective," Journal of Logistics, Informatics and Service Science, vol. 5, no. 1, pp. 31-42, 2018.

[11] M. E. Schweitzer and G. P. Cachon, "Decision bias in the newsvendor problem with a known demand distribution: experimental evidence," Management Science, vol. 46, no. 3, pp. 404-420, 2000.

[12] T. A. Taylor, "Supply chain coordination under channel rebates with sales effort effects," Management Science, vol. 48, no. 8, pp. 992-1007, 2002.

[13] H. Krishnan, R. Kapuscinski, and D. A. Butz, "Coordinating contracts for decentralized supply chains with retailer promotional effort," Management Science, vol. 50, no. 1, pp. 48-63, 2004.

[14] D. Xing and T. Liu, "Sales effort free riding and coordination with price match and channel rebate," European Journal of Operational Research, vol. 219, no. 2, pp. 264-271, 2012.

[15] Y.-C. Tsao and G.-J. Sheen, "Effects of promotion cost sharing policy with the sales learning curve on supply chain coordination," Computers \& Operations Research, vol. 39, no. 8, pp. 1872-1878, 2012.

[16] X. Yu and Z. Wan, "Supply chain financing model under a new mechanish of bankruptcy guarantee," Economic Computation \& Economic Cybernetics Studies \& Research, vol. 54, no. 2, pp. 243-262, 2020.

[17] T. H. Nazifa and K. K. Ramachandran, "Exploring the role of information sharing in supply chain management: a case study," Journal of System and Management Sciences, vol. 8, no. 4, pp. 13-37, 2018.

[18] T. H. Nazifa and K. K. Ramachandran, "Information sharing in supply chain management: a case study between the cooperative partners in manufacturing industry," Journal of System and Management Sciences, vol. 9, no. 1, pp. 19-47, 2019. 